\title{
PRODUÇÃO DE CONCENTRADO PROTEICO DE SORO EM ESCALA PILOTO: ASPECTOS TECNOLÓGICOS
}

\section{Production of whey protein concentrates powder at pilot-scale: technological aspects}

\author{
Renam de Oliveira Moreira ${ }^{1}$, Paulo Henrique Rodrigues Junior ${ }^{\text {, }}$

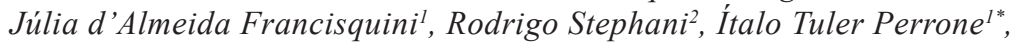 \\ Antônio Fernandes de Carvalho ${ }^{I}$
}

\begin{abstract}
RESUMO
A ultrafiltração de soro de leite, para a produção de concentrados proteicos de soro (CPS) e de isolados proteicos de soro (IPS), é amplamente utilizada em todo o mundo, e estudos de produção em escala piloto possibilitam maior entendimento destas tecnologias. O objetivo deste estudo foi avaliar os aspectos tecnológicos da produção do CPS em escala piloto. Foram realizadas análises físico-químicas no permeado e no retentado em pó em relação aos teores de compostos nitrogenados, acidez, $\mathrm{pH}$, teores de sólidos solúveis, cinzas e atividade de água. A composição dos permeados em diferentes fatores de concentração não apresentou diferenças significativas durante a concentração nas condições de temperatura e pressão utilizadas. O concentrado apresentou variações no teor de proteína total, proteínas do soro, NNP, umidade, cinzas, porém, não apresentou mudanças no $\mathrm{pH}$, o que pode ser atribuído ao aumento do poder tamponante das proteínas. Foi definido o modelo matemático entre as frações nitrogenadas com a concentração, possibilitando calcular o teor aproximado de proteínas de um fator de concentração desejado.

Palavras-chave: ultrafiltração; evaporação a vácuo; spray dryer.
\end{abstract}

\begin{abstract}
The production of whey protein concentrate powder (WPC) and whey protein isolates (WPI) by ultrafiltration are widely used throughout the world and greater

1 Universidade Federal de Viçosa/Departamento de Tecnologia de Alimentos, Campus universitário s/n 36570900,Viçosa, MG, Brasil. E-mail: italotulerperrone@gmail.com

2 Universidade Federal de Juiz de Fora, Departamento de Química, Juiz de Fora, MG, Brasil.

* Autor para correspondência.
\end{abstract}


understanding of these technologies are obtained by pilot scale studies. The aim of this study was to evaluate the impact of technological aspects on the composition of retentates and WPC obtained in pilot scale. The content of nitrogen, acidity, $\mathrm{pH}$, soluble solids, ash and water activity were analysed. The compositions of permeate were not affected by the concentration factor during the ultrafiltration. The concentrated composition was affected by the concentration factor during the ultrafiltration on total protein content, whey protein, NPN, moisture and ash, but not on $\mathrm{pH}$. According to the results, it was calculated the mathematical relation between nitrogen fraction and concentration factor.

Keywords: ultrafiltration; vacuum evaporation; spray dryer.

\section{INTRODUÇÃO}

Os processos de separação por membranas são operações que as utilizam no fracionamento de misturas, soluções e suspensões abrangendo espécies de tamanho e natureza química diferentes. São usados para efetuar grande variedade de separações, sendo definidos como barreiras seletivas ao transporte de massa de certos componentes de uma amostra (BALDASSO, 2008). Dentre estas técnicas destaca-se a Ultrafiltração (UF) que utiliza poros com tamanho médio de 0,1 a $0,01 \mu \mathrm{m}$ e pressões de 1,03 a $7,23 \mathrm{kgf} / \mathrm{cm}^{2}$ (HABERT et. al, 2006).

Esta operação começou a ser utilizada industrialmente a partir da década de 70 , sendo uma alternativa altamente viável para o processamento do soro de leite, pois as proteínas do soro são retidas e a lactose passa pela membrana, obtendo-se assim um retentado final com alto teor de proteínas do soro. Para obter concentrados com maiores teores de proteínas, é utilizada a diálise, que consiste em adicionar água ao concentrado e em seguida eliminar toda a água adicionada através da ultrafiltração. Com isso a quantidade de lactose e sais minerais no concentrado diminuem, originando assim concentrados com maiores teores de proteína em base seca, o que resulta em CPSs com elevado teor proteico (ST-GELAIS et. al., 1992).

Outra grande aplicação que surgiu na mesma década foi a técnica denominada
MMV conforme as iniciais dos nomes de seus inventores (MAUBOIS; MOCQUOT, 1975). Esta técnica consiste em concentrar o leite através de uma membrana de UF até que se obtenham teores de proteína e gordura próximos ao desejado em um queijo, o que foi denominado de líquido pré-queijo. Este processo permite uma padronização do teor de proteínas no queijo, garantindo o mesmo produto final durante as diferentes épocas do ano. A produção de CPS é uma alternativa tecnológica viável ao aproveitamento do soro oriundo das fábricas de queijos, possibilitando a obtenção de produtos com grande valor mercadológico agregado e ocorre por meio da aplicação das técnicas de membranas associadas a evaporação a vácuo e secagem em spray dryer (MAUBOIS, 1991). Hoje esta técnica é usada em diversos países na fabricação de queijos e principalmente para o aproveitamento do soro a fim de produzir concentrado e isolado proteico de soro (CPS e IPS ), já que a presença deste tipo de equipamento, em muitos países, tornou-se tão comum como a de uma centrífuga (CARVALHO; MAUBOIS, 2010).

Devido à grande difusão desta técnica e sua aplicação em processamento de soro de leite é necessário entender o comportamento dos diferentes componentes nitrogenados durante a UF. Este comportamento é altamente influenciado pela temperatura, pressão, $\mathrm{pH}$, composição centesimal do soro e pelos fenômenos de fouling e camada de polarização 
de gel que se formam durante a ultrafiltração. Historicamente, o Brasil caracteriza-se como grande importador de CPS, existindo uma grande carência por informações técnicas, principalmente com embasamento científico, por parte das indústrias de laticínios no tocante às tecnologias para transformação de leite e soro em lácteos desidratados dentro da realidade da qualidade do soro nacional. A determinação da influência do processamento industrial sobre as propriedades químicas e funcionais dos CPS, CPL, IPL é alvo de pesquisas em todo o mundo (THOMAS et al. 2004; ANEMA et al. 2006; KAZEMIMOGHADAM; MOHAMMADI 2007; GAIANI et al. 2009; SUAREZ et al. 2009; RINALDONI et al. 2009; MIMOUNI et al. 2010;THOMSEN et al. 2012), consistindo em ferramenta indispensável para a produção industrial.

Os objetivos deste trabalho foram determinar a composição e alguns atributos físico-químicos de retentados e permeados correspondentes durante a UF, assim como determinar as equações matemáticas que relacionam o fator de concentração empregado no processo com os teores de nitrogênio total, nitrogênio não proteico e nitrogênio solúvel em $\mathrm{pH}$ 4,6 do retentado.

\section{MATERIAL E MÉTODOS}

O experimento consistiu na centrifugação do soro de leite obtido na fabricação de queijo Minas Frescal, realização da UF, coleta dos permeados e retentados com diferentes fatores de concentração, realização das análises físico químicas: umidade pelo método gravimétrico, cinzas pela incineração em mufla a $550{ }^{\circ} \mathrm{C}$, acidez por meio de titulação com hidróxido de sódio padronizado a $0,1 \mathrm{~mol} \cdot \mathrm{L}^{-1}$ (AOAC, 2005), $\mathrm{pH}$ (pHmetro de bancada DM 20, Digimed), teor de sólidos solúveis (Refratômetro óptico manual, Alla France) e atividade de água (AquaLab models 3TE, Decagon Devices, Inc.). As de- terminações dos teores de nitrogênio total, solúvel em $\mathrm{pH}$ 4,6 e nitrogênio solúvel em TCA $12 \%\left(\mathrm{~m}^{\cdot} \mathrm{v}^{-1}\right)$ foram empregados para calcular os teores de proteína total (PT), proteínas solúveis (PS) e nitrogênio não proteico (NNP), respectivamente,com os fatores de conversão de nitrogênio de 6,38, 6,25 e 6,19 conforme descrito em Wehr; Frank (2004). Foi determinado o teor de caseínas (CS) e de Proteínas do soro (PtS) através das Equações 1 e 2, conforme FIL 20B:1993:

$$
\begin{aligned}
& C S=P T-P S \\
& P t S=P S-N N P
\end{aligned}
$$

Para as amostras de permeado não foi realizada analise de NS pH 4,6, pois segundo Maubois; Mocquot (1975), toda a caseína fica retira no retentado, por membranas de $10 \mathrm{kDa}$. Empregou-se uma planta piloto de ultrafiltração (UF) da marca "WGM Sistemas" com uma membrana espiral de polissulfona/ poliamida (Koch Membranes), porosidade $10 \mathrm{kDa}$, área filtrante de $3,0 \mathrm{~m}^{2}$ e diferença de pressão de $2,2 \mathrm{kgf} / \mathrm{cm}^{2}$. Na Figura 1 é apresentada a foto da planta piloto de UF empregada no experimento.

O cálculo para a determinação do fator de retenção de nitrogênio foi realizado conforme Bohner; Bradley (1992), e é apresentado na equação 3 .

$$
R N=1-\frac{P T P}{P T R}
$$

sendo: $\mathrm{RN}=$ fator de retenção de nitrogênio, $\mathrm{PTR}=$ teor de proteína total do retentado, $\mathrm{PTP}=$ teor de proteína total do permeado correspondente.

Durante a ultrafiltração pode-se optar em usar 2 tipos de processamento: processamento a frio e processamento a quente. No processamento a quente para lácteos são utilizadas temperaturas entre $40{ }^{\circ} \mathrm{C}$ e $65^{\circ} \mathrm{C}$, 
como vantagens temos menor viscosidade do produto o que acarreta menor tempo de processamento, porém como desvantagens temos precipitação de sais de cálcio, desnaturação de proteínas termosensíveis (especialmente a $\beta$-lactoglobulina) e o crescimento de microorganismos termofílicos e termodúricos. No entanto no processamento a frio onde são utilizadas temperaturas de até $30{ }^{\circ} \mathrm{C}$, como vantagens temos aumento na retenção de proteínas, os problemas com precipitação de sais e desnaturação de proteínas são eliminados, além da redução da multiplicação de micro-organismos (SILVA, 1995; CHERYAN, 1998; BOSCHI, 2006). Neste trabalho usamos temperaturas entre $45^{\circ} \mathrm{C}$ e $50^{\circ} \mathrm{C}$, para que o tempo de processamento fosse menor, porém tentando controlar a precipitação de sais e a desnaturação das proteínas.

As amostras de retentados e seus respectivos permeados foram coletadas e estocadas em frascos de vidro a $-20{ }^{\circ} \mathrm{C}$ até serem analisadas. Através dos resultados determinou-se o ajuste dos dados aos modelos linear e exponencial por meio do programa Origin ${ }^{\circledR}$ 5.0 , sendo calculado o valor do coeficiente de correlação $\left(\mathrm{R}^{2}\right)$, o coeficiente de correlação de Pearson (CP) e a significância estatística dos dados ao modelo matemático $(\mathrm{P})$.

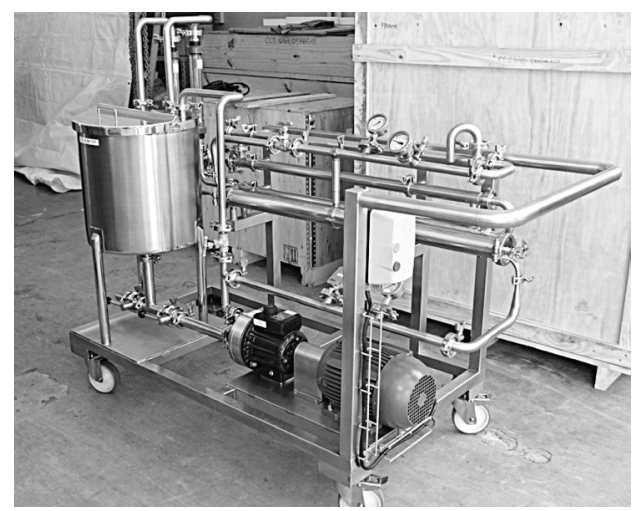

Figura 1 - Sistema de UF empregado no experimento
O processo de evaporação a vácuo ocorreu à temperatura de $60{ }^{\circ} \mathrm{C} \pm 2{ }^{\circ} \mathrm{C}$ em evaporador rotativo microprocessado de bancada da marca Quimis modelo Q344M. A evaporação foi conduzida objetivando encontrar um fator de concentração igual a 4. O evaporado produzido foi conduzido a um condensador de contato indireto no qual a temperatura da água de resfriamento foi controlada em $15^{\circ} \mathrm{C}$ $\pm 2{ }^{\circ} \mathrm{C}$. Após o cálculo da quantidade de água que deveria ser evaporada em cada repetição, visando alcançar o fator de concentração desejado, realizou-se a evaporação até o volume exato calculado de evaporado, que foi medido em proveta. Na Figura 2 é apresentado o evaporador rotativo durante a concentração das amostras.

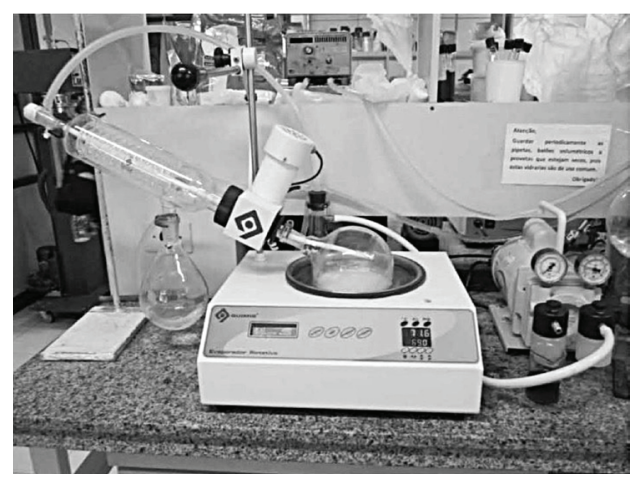

Figura 2 - Evaporador rotativo utilizado no experimento

Tabela 1 - Condições empregadas durante a produção do CPS $(\mathrm{n}=3)$

\begin{tabular}{c|c|c}
\hline Tratamento & $\begin{array}{c}\text { Temperatura } \\
\text { do ar de } \\
\text { entrada } \\
\left({ }^{\circ} \mathrm{C}\right)\end{array}$ & $\begin{array}{c}\text { Teor de sólidos } \\
\text { solúveis no } \\
\text { spray dryer } \\
\left({ }^{\circ} \text { Brix }\right)\end{array}$ \\
\hline T1 & $130 \pm 5$ & $15,7 \pm 1,9$ \\
T2 & $145 \pm 5$ & $47,1 \pm 1,9$ \\
T3 & $130 \pm 5$ & $15,7 \pm 1,9$ \\
T4 & $145 \pm 5$ & $47,1 \pm 1,9$ \\
\hline
\end{tabular}


O delineamento foi inteiramente casualisado com 4 tratamentos e 3 repetições de cada tratamento totalizando 12 produções. Todas as etapas do trabalho foram realizadas no Departamento de Tecnologia de Alimentos da UFV. O evaporador rotativo microprocessado e o spray dryer de único estágio pertencem a Gemacom Tech e estão instalados no INOVALEITE - Laboratório de Ciência e Tecnologia de Leite e Derivados do Departamento de Tecnologia de Alimentos da
UFV por meio de uma parceria de pesquisa público-privada.

\section{RESULTADOS E DISCUSSÃO}

Os retentados e permeados coletados durante a ultrafiltração são apresentados na Figura 3.

$\mathrm{Na}$ Tabela 2 encontram-se os resultados das análises físico-químicas dos retentados e seus respectivos permeados.

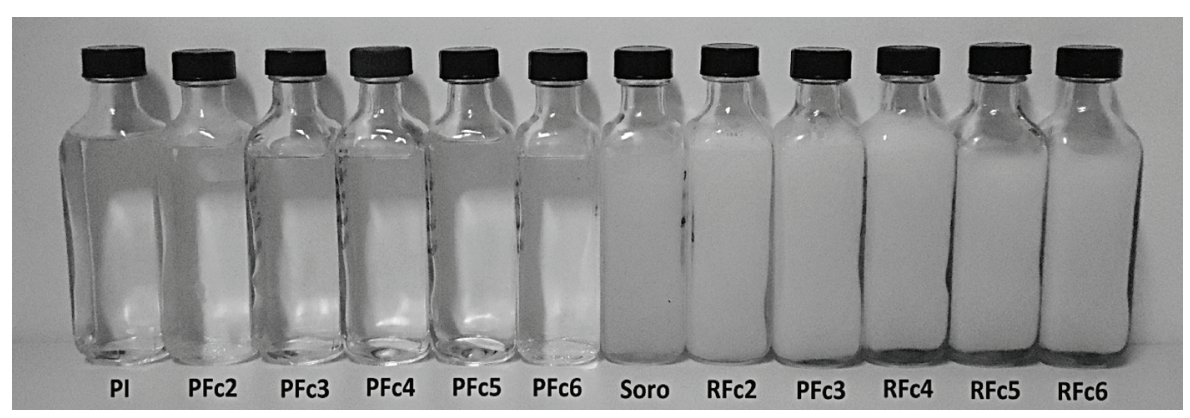

Figura 3 - Retentados e Permeados coletados no experimento

Tabela 2 - Composição centesimal dos retentados e permeados $(n=3)$

\begin{tabular}{cccccccc}
\hline & PT & NNP & PtS & Umidade & Cinzas & ${ }^{\circ}$ Brix & pH \\
\hline Soro & $0,87(0,03)^{\mathrm{f}}$ & $0,21(0,01)^{\text {de }}$ & $0,66(0,03)^{\mathrm{f}}$ & $93,7(0,1)^{\mathrm{abc}}$ & $0,51(0,01)^{\text {efg }}$ & $6,2(0,0)^{\text {ef }}$ & $6,28(0,09)^{\mathrm{a}}$ \\
\hline PI & $0,18(0,01)^{\mathrm{g}}$ & $0,14(0,06)^{\mathrm{f}}$ & $0,04(0,03)^{\mathrm{g}}$ & $95,6(0,1)^{\mathrm{a}}$ & $0,44(0,03)^{\mathrm{g}}$ & $4,2(0,0)^{\mathrm{f}}$ & $6,26(0,03)^{\mathrm{a}}$ \\
\hline PFc2 & $0,19(0,00)^{\mathrm{g}}$ & $0,14(0,06)^{\mathrm{f}}$ & $0,05(0,03)^{\mathrm{g}}$ & $95,8(0,3)^{\mathrm{a}}$ & $0,47(0,05)^{\mathrm{fg}}$ & $4,5(0,5)^{\mathrm{f}}$ & $6,21(0,08)^{\mathrm{a}}$ \\
\hline PFc3 & $0,17(0,03)^{\mathrm{g}}$ & $0,15(0,06)^{\mathrm{f}}$ & $0,02(0,02)^{\mathrm{g}}$ & $95,3(0,7)^{\mathrm{ab}}$ & $0,49(0,06)^{\mathrm{efg}}$ & $4,7(0,6)^{\mathrm{f}}$ & $5,81(0,77)^{\mathrm{a}}$ \\
\hline PFc4 & $0,17(0,03)^{\mathrm{g}}$ & $0,15(0,06)^{\mathrm{f}}$ & $0,02(0,02)^{\mathrm{g}}$ & $95,3(0,9)^{\mathrm{a}}$ & $0,49(0,02)^{\mathrm{efg}}$ & $4,6(0,9)^{\mathrm{f}}$ & $5,68(0,85)^{\mathrm{a}}$ \\
\hline PFc5 & $0,19(0,05)^{\mathrm{g}}$ & $0,15(0,06)^{\mathrm{f}}$ & $0,04(0,02)^{\mathrm{g}}$ & $95,3(1,5)^{\mathrm{ab}}$ & $0,51(0,04)^{\mathrm{efg}}$ & $4,7(1,3)^{\mathrm{f}}$ & $5,89(0,27)^{\mathrm{a}}$ \\
\hline PFc6 & $0,23(0,02)^{\mathrm{g}}$ & $0,17(0,06)^{\mathrm{ef}}$ & $0,06(0,02)^{\mathrm{g}}$ & $94,8(1,4)^{\mathrm{ab}}$ & $0,56(0,05)^{\mathrm{def}}$ & $5,2(1,2)^{\mathrm{f}}$ & $5,50(0,87)^{\mathrm{a}}$ \\
\hline RFc2 & $1,36(0,45)^{\mathrm{e}}$ & $0,30(0,10)^{\mathrm{d}}$ & $1,06(0,06)^{\mathrm{e}}$ & $92,1(0,6)^{\mathrm{bcd}}$ & $0,59(0,02)^{\mathrm{cde}}$ & $8,4(0,5)^{\mathrm{de}}$ & $6,22(0,18)^{\mathrm{a}}$ \\
\hline RFc3 & $1,82(0,58)^{\mathrm{d}}$ & $0,31(0,04)^{\mathrm{cd}}$ & $1,51(0,03)^{\mathrm{d}}$ & $90,7(0,8)^{\mathrm{cde}}$ & $0,64(0,03)^{\mathrm{bcd}}$ & $9,7(0,3)^{\mathrm{cd}}$ & $5,65(0,90)^{\mathrm{a}}$ \\
\hline RFc4 & $2,45(0,56)^{\mathrm{c}}$ & $0,43(0,14)^{\mathrm{bc}}$ & $2,02(0,05)^{\mathrm{c}}$ & $89,5(0,9)^{\mathrm{de}}$ & $0,68(0,04)^{\mathrm{abc}}$ & $11,5(0,8)^{\mathrm{bc}}$ & $5,35(0,87)^{\mathrm{a}}$ \\
\hline RFc5 & $3,01(0,94)^{\mathrm{b}}$ & $0,54(0,19)^{\mathrm{b}}$ & $2,47(0,12)^{\mathrm{b}}$ & $87,6(1,3)^{\text {ef }}$ & $0,74(0,05)^{\mathrm{ab}}$ & $13,5(1,4)^{\mathrm{ab}}$ & $5,13(0,90)^{\mathrm{a}}$ \\
\hline RFc6 & $4,35(0,10)^{\mathrm{a}}$ & $0,62(0,21)^{\mathrm{a}}$ & $3,73(0,30)^{\mathrm{a}}$ & $85,7(2,3)^{\mathrm{f}}$ & $0,78(0,06)^{\mathrm{a}}$ & $15,4(2,0)^{\mathrm{a}}$ & $5,05(0,91)^{\mathrm{a}}$ \\
\hline
\end{tabular}

Sendo: $\mathrm{P}=$ permeado de ultrafiltração, $\mathrm{R}=$ retentado de ultrafiltração, $\mathrm{DP}=$ desvio padrão, $\mathrm{M}=\mathrm{média}, \mathrm{FC}=$ fator de concentração, $\mathrm{PT}=$ proteína total, $\mathrm{NNP}=$ nitrogênio não proteico e $\mathrm{PtS}=$ proteínas do soro. Média seguidas de letras iguais na coluna não diferem estatisticamente ao nível de significância de $5 \%$ pelo teste de Tuckey. 
Não houve diferença significativa entre os teores de nitrogênio solúvel em $\mathrm{pH}$ 4,6 e o teor de nitrogênio total, indicando ausência de caseína no soro após as operações de centrifugação e UF.

Na Tabela 3 encontram-se os valores calculados do percentual de retenção de nitrogênio (Proteína Total) e a relação dos teores de NNP e PtS.

Tabela 3 - Valores de retenção de nitrogênio (proteína total) e a relação dos teores de NNP e PtS

\begin{tabular}{c|c|c}
\hline & $\begin{array}{c}\text { Retenção de } \\
\text { Nitrogênio (\%) }\end{array}$ & NNP/PtS \\
\hline Soro & 81,298 & 0,323 \\
FC 2 & 89,528 & 0,179 \\
FC 3 & 92,061 & 0,157 \\
FC 4 & 93,817 & 0,144 \\
FC 5 & 94,649 & 0,132 \\
FC 6 & 95,318 & 0,134 \\
\hline
\end{tabular}

Durante a UF o percentual de retenção de nitrogênio aumentou, o que pode provar a concentração das $\mathrm{PtS}$. Tal elevação na retenção se deve também a proporção de NNP/PtS ter diminuído ao longo do processo, o que indica que durante a concentração, há grande perda de NNP no permeado e a concentração de PtS no retentado final.

As relações matemáticas entre o fator de concentração durante a ultrafiltração e os teores de proteína total, proteínas do soro e nitrogênio não proteico dos retentados são apresentados nas Equações 1, 2 e 3.

$$
\begin{aligned}
& \mathrm{PT}=0,7324 \times(\mathrm{FC})+0,066 \\
& \left(\mathrm{P}<0,0001, \mathrm{R}^{2}=0,9983, \mathrm{CP}=0,9966\right) \\
& \mathrm{PtS}=0,6654 \times(\mathrm{FC})-0,0459 \\
& \left(\mathrm{P}<0,0001, \mathrm{R}^{2}=0,9986, \mathrm{CP}=0,9972\right)
\end{aligned}
$$

$$
\begin{aligned}
& \mathrm{NNP}=0,1708 \text { e } 0,1889 \times(\mathrm{FC}) \\
& \left(\mathrm{P}<0,0001, \mathrm{R}^{2}=0,9941, \mathrm{CP}=0,9829\right)
\end{aligned}
$$

A partir das Equações 1 e 2 pode-se verificar que o comportamento durante a concentração de proteína total e proteínas do soro se ajustaram melhor ao modelo linear. Já a Equação 3 obteve melhor ajuste através do modelo exponencial. Este aumento exponencial na retenção de NNP (Equação 3) pode estar associado à formação da camada de polarização de gel e ao fouling (BALDASSO, 2008), que se formam e aumentam durante a ultrafiltração do soro. Este aumento na retenção até certo ponto é controlável e pode ser desejável, pois aumenta o teor de NT no produto final. Quando há a formação de uma camada de polarização de gel excessiva, a membrana além de reter o NNP poderá também reter grandes teores de lactose e sais de cálcio, o que resultaria em um pó com menores teores de proteína e maiores teores de lactose. Isso seria um problema na produção de WPIs, além de fluxos de permeados muito baixos que aumentaria muito o tempo de operação (VYAS; TONG, 2003). Os CPSs são classificados de acordo com o teor de proteína, que vão de $34 \%$ a $89 \%$ e os WPIs a partir 90\% de proteínas. Quanto maior o teor de proteínas destes produtos, maior é o valor agregado sobre ele (USDEC, 2008 apud EVANS et. al., 2010).

A composição dos CPSs é apresentada na Tabela 4.

O teor médio de proteínas dos pós ficou próximo a $30 \%$, não sendo identificada diferença significativa entre os tratamentos. Os fatores de concentração empregados durante a ultrafiltração podem ser elevados visando à obtenção de CPS com, no mínimo, $35 \%$ de proteína, ou pode-se realizar a diálise que aumenta a relação proteínas em base seca. O teor de $35 \%$ de proteínas é um valor de referência dentro dos produtos produzidos 
Tabela 4 - Composição dos concentrados proteicos de soro em pó obtidos no experimento $(\mathrm{n}=3)$

\begin{tabular}{lcccc}
\hline & Proteína Total & Umidade & Cinzas & Atividade de água \\
\hline CPS $_{1}$ & $29,43(3,73)^{\mathrm{a}}$ & $4,70(0,82)^{\mathrm{a}}$ & $5,36(0,82)^{\mathrm{a}}$ & $0,234(0,070)^{\mathrm{a}}$ \\
$\mathrm{CPS}_{2}$ & $29,92(4,43)^{\mathrm{a}}$ & $5,32(0,81)^{\mathrm{a}}$ & $5,36(0,83)^{\mathrm{a}}$ & $0,284(0,052)^{\mathrm{a}}$ \\
$\mathrm{CPS}_{3}$ & $29,54(3,97)^{\mathrm{a}}$ & $5,10(0,13)^{\mathrm{a}}$ & $5,28(0,92)^{\mathrm{a}}$ & $0,259(0,048)^{\mathrm{a}}$ \\
$\mathrm{CPS}_{4}$ & $29,94(3,92)^{\mathrm{a}}$ & $4,32(0,74)^{\mathrm{b}}$ & $5,36(0,88)^{\mathrm{a}}$ & $0,174(0,014)^{\mathrm{b}}$ \\
$\mathrm{CPS}_{1+2}$ & $29,69(4,51)^{\mathrm{a}}$ & $5,11(0,41)^{\mathrm{a}}$ & $5,41(0,83)^{\mathrm{a}}$ & $0,247(0,026)^{\mathrm{a}}$ \\
$\mathrm{CPS}_{3+4}$ & $30,82(4,16)^{\mathrm{a}}$ & $4,52(1,31)^{\mathrm{a}}$ & $5,77(0,86)^{\mathrm{a}}$ & $0,206(0,076)^{\mathrm{ab}}$ \\
\hline
\end{tabular}

Sendo: $\mathrm{CPS}_{\mathrm{X}}=$ concentrado proteico de soro obtido pelo tratamento $\mathrm{X} ; 1=$ temperatura do ar de secagem em $130{ }^{\circ} \mathrm{C}$ e retentado não concentrado por evaporação a vácuo; $2=$ temperatura do ar de secagem em $145^{\circ} \mathrm{C}$ e retentado não concentrado por evaporação a vácuo; 3 = temperatura do ar de secagem em $130^{\circ} \mathrm{C}$ e retentado concentrado por evaporação a vácuo; $4=$ temperatura do ar de secagem em $145^{\circ} \mathrm{C}$ e retentado concentrado por evaporação a vácuo; $1+2=$ pó retido na câmara de secagem durante os tratamentos 1 e $2 ; 3+4=$ pó retido na câmara se secagem durante os tratamentos 3 e 4 . Média seguidas de letras iguais na coluna não diferem estatisticamente ao nível de significância de $5 \%$ pelo teste de Tuckey.

pelas indústrias, possuindo grande espectro de aplicação.

Com relação ao teor de umidade dos pós, o $\mathrm{CPS}_{4}$ apresentou menor teor que os demais, o que resulta também em uma menor atividade de água. O teor de umidade dos produtos lácteos desidratados é um importante atributo a ser controlado pelas indústrias devido a exigências de legislação, rendimento industrial e para a conservação do produto final. Visando entender e controlar as modificações químicas nos constituintes dos lácteos desidratados, durante o prazo de armazenamento, deve-se analisar principalmente a atividade de água dos mesmos. Para produtos alimentícios amorfos como o leite em pó e concentrados proteicos em pó, a estabilidade durante o armazenamento está relacionada à temperatura de transição vítrea (Tg) do mesmo (VUATAZ, 2002; SCHUCK et al, 2005; PATEL et al, 2010). A atividade de água crítica, aquela na qual o produto apresenta baixa Tg para a lactose pura é de 0,370 (JOUPPILA; ROOS, 1994).

Segundo Thomas et al (2004), a transição vítrea está relacionada a difusão molecular e a viscosidade. Desta forma, em produtos alimentícios amorfos é necessário o fornecimento de energia na forma de calor (temperaturas superiores a Tg) para promover esta transição e consequentemente as modificações químicas como escurecimento, perda de fluidez e perda de solubilidade. Leite em pó com atividade de água de 0,370 apresenta Tg igual a $24^{\circ} \mathrm{C}$, enquanto que com atividade de 0,200 apresenta $\mathrm{Tg}$ igual a $50{ }^{\circ} \mathrm{C}$ (ROOS, 2002). Apenas o LPD apresentou atividade de água inferior a 0,200, uma vez que todos os outros produtos avaliados apresentaram valores superiores, o que segundo Roos (2002), faz com que estes lácteos apresentem Tg inferior a $50{ }^{\circ} \mathrm{C}$. Os soros em pó (SPNP, SP0,05 e SP0,1) apresentaram teores de umidade superiores a $4.00 \% \mathrm{~m} \cdot \mathrm{m}^{-1} \mathrm{o}$ que de acordo com Shuck et al (2004) pode possibilitar ao aparecimento de problemas durante a estocagem, como mudanças na coloração e empedramento do pó. As temperaturas de entrada e de saída do ar no spray dryer foram padronizadas durante a realização do experimento, contudo, valores elevados de umidade nos pós indicam que estes controles não foram suficientes.

Segundo Schuck et al. (2008), o controle da temperatura do ar de saída do spray dryer nem sempre é o melhor atributo para o controle da umidade dos pós, pois esta 
propriedade também é muito afetada pelo teor de umidade relativa do ar na entrada e saída do spray dryer. $\mathrm{O}$ equipamento de secagem empregado neste experimento não possui termohigrômetros e sistemas para a medição e controle da umidade do ar de entrada e saída da câmara, o que impossibilitou este controle e como consequência os produtos apresentaram umidade superior a $4 \% \mathrm{~m} \cdot \mathrm{m}-1$. Dadas às condições de realização do experimento, do equipamento (impossibilidade de controle da umidade relativa do ar) e aos teores de umidade obtido nos pós sugere-se um aumento nas temperaturas do ar de entrada e de saída da câmara de secagem em trabalhos futuros visando à diminuição da umidade dos pós. De acordo com Písecký (1997) as temperaturas de secagem empregadas em spray dryer para produtos lácteos variam entre 170 a $230{ }^{\circ} \mathrm{C}$ para o ar de entrada e entre 70 e $90{ }^{\circ} \mathrm{C}$ para o ar de saída.

Segundo Schuck et al. (2008), os lácteos desidratados devem apresentar uma atividade de água de 0,200, visando a minimização das reações químicas e bioquímicas, assim como o desenvolvimento microbiano. Este valor é recomendado quando a conservação do produto ocorre a temperaturas inferiores a $50{ }^{\circ} \mathrm{C}$. Os produtos desidratados obtidos no experimento apresentaram valor de atividade de água superior a 0,200, indicando que modificações nas suas características podem ocorrer em uma velocidade elevada durante o armazenamento.

\section{CONCLUSÕES}

Os atributos de composição avaliados nos permeados não são afetados pelo fator de concentração durante a ultrafiltração nas condições de temperatura e pressão utilizadas no experimento. Os teores de proteína total, proteínas do soro, NNP, umidade e cinzas do retentado são afetados pelo fator de concentração, contudo o pH não varia.
Observou-se aumento na retenção de nitrogênio durante a concentração, o que explica a eficiência da membrana em reter as frações nitrogenadas do soro. Estabeleceu-se um modelo matemático que relaciona os teores das frações nitrogenadas com o fator de concentração durante a ultrafiltração. Nas condições do experimento o fator de concenração igual a 6 para soro foi insuficiente para a produção de CPSs com $35 \%$ de proteína. Os produtos desidratados obtidos no experimento apresentaram valor de atividade de água superior a 0,200 , indicando que modificações nas suas características podem ocorrer em uma velocidade elevada durante o armazenamento.

\section{AGRADECIMENTOS}

Os autores agradecem a FAPEMIG, a CAPES e ao CNPq pelo apoio financeiro a realização dos experimentos e pelas bolsas de produtividade dos autores.

\section{REFERÊNCIAS}

ANEMA, S. G. et al. Effects of storage temperature on the solubility of milk protein concentrate (MPC85). Food Hydrocolloids, v. 20, n. 2-3, p. 386-393, 2006.

AOAC - Official methods of analysis of AOAC International, AOAC International. 18th ed. Maryland: AOAC, 2005.

\section{BALDASSO, C. Concentração, Purificação e Fracionamento das Proteínas do Soro Lácteo através da Tecnologia de Separação por Membranas. 2008. 163f. Dissertação (Mestrado em Engenharia) - Universidade Federal do Rio Grande do Sul, Escola de Engenharia, Porto Alegre, 2008.}

BOHNER, H. F.; BRADLEY, R. L. Effective cleaning and sanitizing of polysulfone ultrafiltration membrane systems. Journal of Dairy Science, v. 75, n. 3, p. 718-724, 1992. 
BOSCHI, J. R. Concentração e purificação das proteínas do soro de queijo por ultrafiltração. 2006. 105f. Dissertação (Mestrado em Engenharia) - Universidade Federal do Rio Grande do Sul, Escola de Engenharia, Porto Alegre, 2006.

CARVAlHO, A. F et al. Applications of membrane technologies in the dairy industry. In: COIMBRA, J. S. R. et al. Engineering aspects of milk and dairy products. Boca Raton: CRC Press, 2010. p. 33-55.

\section{CHERYAN, M. Ultrafiltration and Micro-} filtration Handbook. Lancaster: Technomic, 1998. 254p.

EVANS, J. et al. Comparison of composition and sensory properties of $80 \%$ whey protein and milk serum protein concentrates. Journal of Dairy Science, v. 93, n. 5, p. 18241843, 2010.

GAIANI, C. et al. Native phosphocaseinate powder during storage: Lipids released onto the surface. Journal of Food Engineering, v. 94, p. 130-134, 2009.

HABERT, A. C. et al. Processos de separação por membranas. Rio de Janeiro: e-papers, 2006. 180p.

JOUPPILA, K.; ROOS, Y.H. Water sorption and time-dependent phenomena of milk powders. Journal of Dairy Science, v. 77, n. 7, p. 1798-1808, 1994.

KAZEMIMOGHADAM, M. et al. Chemical cleaning of ultrafiltration membranes in the milk industry. Desalination, v. 204, n. 1-3, p. 213-218, 2007.

MAUBOIS, J. L. New applications of membrane technology in the dairy industry. Australian Journal of Dairy Technology, v. 46, p. 91-95, 1991.
MAUBOIS, J. L.; MOCQUOT, G. Aplication of membrane ultrafiltration to preparation of various types of cheese. Journal of Dairy Science, v. 58, n. 7, p. 1001-1007, 1975.

MIMOUNI, A. et al. Investigation of the microstructure of milk protein concentrate powders during rehydration: Alterations during storage. Journal of Dairy Science, v. 93, n. 2, p. 463-472, 2010.

PATEL, K. et al. One dimensional simulation of cocurrent, dairy spray drying systems pros and cons. Dairy Science and Technology, v. 90, n. 2-3, p. 181-210, 2010.

PÍSECKÝ, J. Handbook of milk powder manufacture. Copenhagen: NIRO, 1997. $261 p$.

RINALDONI, A. N. et al. Assessing performance of skim milk ultrafiltration by using technical parameters. Journal of Food Engineering, v. 92, n. 2, p. 226-232, 2009.

ROSS, Y. H. Importance of glass transition and water activity to spray drying and stability of dairy powders. Le Lait, v. 82, n. 4, p. 475484, 2002.

SCHUCK, P. et al. Water activity and glass transition in dairy ingredients. Le Lait, v. 85, n. 4-5, p. 295-304, 2005.

SCHUCK, P. Et al. Séchage des lactosérums et dérivés: rôle du lactose et de la dynamique de l'eau. Le Lait, v. 84, n. 3, p. 243-268, 2004.

SHUCK, P. et al. Relative humidity of outlet air: the key parameter to optimize moisture content and water activity of dairy powders. Dairy Science and Technology, v. 88, n. 1, p. 45-52, 2008.

SILVA, F. T. Concentração de suco de laranja (Citrus sinensis) por osmose inversa. 1995. 
110f. Dissertação (Mestrado em Tecnologia de Alimentos) - Universidade Estadual de Campinas, Faculdade de Engenharia de Alimentos, Campinas, 1995.

ST-GELAIS, D. et al. Combined effects of temperature, acidification, and diafiltration on composition of skim milk retentate and permeate. Journal of Dairy Science, v. 75, n. 5, p. 1167-1172, 1992.

SUAREZ, E. et al. Demineralization of whey and milk ultrafiltration permeate by means of nanofiltration. Desalination, v. 241, n. 1-3, p. 272-280, 2009.

THOMAS, M. E. C. et al. Lactose/ $\beta$-lactoglobulin Interaction During Storage of Model Whey Powders. Journal of Dairy Science, v. 87, n. 5, p. 1158-1166, 2004.

THOMAS, M. E. C. et al. Milk powders ageing: effect on physical and functional properties. Critical Reviews in Food Science and Nutrition, v. 44, n. 4, p. 297-322, 2004.

THOMSEN, M. K. Effect of water activity, temperature and $\mathrm{pH}$ on solid state lactosylation of $\beta$-lactoglobulin. International Dairy Journal, v. 23, n. 1, p. 1-8, 2012.

VUATAZ, G. The phase diagram of milk: a new tool for optimizing the drying process. Le Lait, v. 82, n. 4, p. 485-500, 2002.

VYAS, H. K.; TONG, P. S. Process for calcium retention during skim milk ultrafiltration. Journal of Dairy Science, v. 86, n. 9, p. 27612766, 2003.

WEHR, H. M. W.; FRANK, J. F. Standard Methods for The Examination of Dairy Products. In: . American Public Health Association. Washington:APHA, 2004. 